\title{
Article \\ The Effect of Regular Physical Activity on Muscle and Adipose Tissue in Premenopausal Women
}

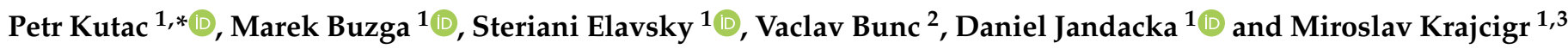 \\ 1 Department of Human Movement Studies, University of Ostrava, 70103 Ostrava, Czech Republic; \\ marek.buzga@osu.cz (M.B.); steriani.elavsky@osu.cz (S.E.); daniel.jandacka@osu.cz (D.J.); \\ miroslav.krajcigr@osu.cz (M.K.) \\ 2 Faculty of Physical Education and Sport, Charles University, Praha 6, 16252 Praha, Czech Republic; \\ bunc@ftvs.cuni.cz \\ 3 Faculty of Physical Education and Sport, University of South Bohemia, \\ 37005 České Budějovice, Czech Republic \\ * Correspondence: petr.kutac@osu.cz
}

Citation: Kutac, P.; Buzga, M.; Elavsky, S.; Bunc, V.; Jandacka, D.; Krajcigr, M. The Effect of Regular Physical Activity on Muscle and Adipose Tissue in Premenopausal Women. Appl. Sci. 2021, 11, 8655. https://doi.org/10.3390/app11188655

Academic Editors: Stefano Masiero and Jesús García Pallarés

Received: 23 June 2021

Accepted: 15 September 2021

Published: 17 September 2021

Publisher's Note: MDPI stays neutral with regard to jurisdictional claims in published maps and institutional affiliations.

Copyright: () 2021 by the authors. Licensee MDPI, Basel, Switzerland. This article is an open access article distributed under the terms and conditions of the Creative Commons Attribution (CC BY) license (https:// creativecommons.org/licenses/by/ $4.0 /)$

\begin{abstract}
Regular physical activity (PA) plays an important role in the prevention of several noninfectious chronic diseases, partly due to its positive effects on body composition. The relationship between the amount of weekly PA and body composition in premenopausal women, however, remains unclear. The objective of the study is to assess the relationship between body composition and the volume of PA in full-time employed premenopausal women. The study included 136 women (aged $41.07 \pm 2.77$ years). The women were divided into tertiles (T1-T3) according to the level of total reported weekly PA. T1 were women with the lowest volume of PA, T2 were women with a medium volume, and T3 were women with the highest PA volume. DXA was used to measure body mass (BM), body fat (BF), visceral fat (VFA), and fat-free mass (FFM). For the comparison of means, we used one-way ANOVA and a $t$ test. Practical significance was verified with effect of size. Significant differences were found between women in T1 vs. T2 and T1 vs. T3. When compared with T2, T1 women had a higher BM $(+6.10 \mathrm{~kg}), \mathrm{BF}(+5.98 \mathrm{~kg}), \mathrm{BF}(+5.42 \%)$, and $\mathrm{VF}\left(+17.49 \mathrm{~cm}^{2}\right)$. When compared with T3, T1 women had a higher BM $(+5.99 \mathrm{~kg}), \mathrm{BF}(+6.42 \mathrm{~kg}), \mathrm{BF}(+5.89 \%)$, and VFA $\left(+20.71 \mathrm{~cm}^{2}\right)$. We can conclude that a higher volume of weekly PA is associated with lower BF, but appears to have no effect on FFM.
\end{abstract}

Keywords: physical activity; body composition; whole body analysis; segmental analysis; appendicular index; weight status

\section{Introduction}

Between 2013 and 2018, the prevalence of physical inactivity (PIA) in middle-aged women increased substantially in the countries of the European Union (EU) [1]. Moreover, the World Health Organization (WHO) reported a 15\% prevalence of obesity in women [2]. Middle-aged women approaching menopause often see body fat increase and fat-free mass decrease [3]. Adipose tissue considerably contributes to maintaining the energy homeostasis of a healthy human body. A dysfunction in the formation of endocrine mediators (such as adipokines) may lead to the occurrence of serious metabolic diseases besides obesity, including metabolic syndrome, lipodystrophy, and cachexia [4]. Current study has indicated a strong relation between adipose and muscle tissue [5]. Unlike that in healthy and slim individuals, adipose tissue in obese people creates proinflammatory adipokines that induce and exacerbate the weakening of muscle mass and strength. This results in the ectopic accumulation of fat in the skeletal muscles and in creating a positive feedback on adipose tissue [6]. Increased weight (overweight and obesity) usually leads to a reduction in the overall amount of physical activity. Consequently, muscles that are not used decrease in mass. Individuals who do not perform physical activity experience 
a regular loss of FFM and, thus, muscle mass of $0.34-1.28 \%$ per year, starting at the age of 30 [7]. This reduction rapidly increases in women about two years before their final menstrual period (FMP) [3]. Muscles infiltrated with fat tissue inhibit the muscle crosssection from corresponding with their produced strength [4]. Such changes can lead to an early stage of sarcopenia. Sarcopenia is a serious muscle disease, characterized by low levels of three parameters: muscle strength, quality/quantity of muscle tissue, and physical performance [8]. Sarcopenia limits everyday function and contributes to invalidity, decreasing one's independence and self-reliance $[9,10]$. The risk of sarcopenia increases with age, and it is most prevalent in individuals $60+$ years of age [11,12]. Nonetheless, study data from Bijlsma et al. [13] illustrated a prevalence in women younger than 60 of $1.6-15.6 \%$, depending on age and the diagnostic criteria used. Considering that an early diagnosis of sarcopenia is essential for successful treatment [14], it is important to gather data on the quality of muscle tissue and the level of physical activity of women approaching menopause. Evidence indicates that sarcopenia can be prevented, delayed, or even reversed with suitable intervention of exercise [15]. One of the options for assessing sarcopenia is using body composition to calculate the appendicular index, based on the DXA measurement [16].

Regular physical activity (PA) is important in the prevention of many noninfectious chronic diseases, such as cardiovascular diseases, cancer, type 2 diabetes, obesity, bone health degradation, and increased disability. Physical activity is a fundamental life need and its lack influences the individual's basic morphology, state of health, well-being, and physical performance [17-19]. Importantly, PA is a modifiable, controllable parameter that considerably influences the individual's condition [20]. In contrast, physical inactivity, in combination with inappropriate nutrition and increased stress, increases the risk of occurrence of the abovementioned diseases. There is strong research evidence that a sedentary lifestyle is more common in obese individuals than in individuals with normal weight [21]. Middle-aged women should follow the recommendations of WHO for PA, designed for a healthy adult population (18-64 years old). The recommendation is for a minimum of $150 \mathrm{~min}$ of moderate-intensity aerobic PA, or at least a minimum of $75 \mathrm{~min}$ of vigorous-intensity aerobic PA per week [22]. Unfortunately, available population data confirm the failure to follow the recommendations, resulting in insufficient physical activity, especially in populations in Latin America and the Caribbean, south Asia, and high-income Western countries [23]. In total, $42.3 \%$ of women undertake insufficient PA, $11.1 \%$ more than men. Studies dealing with PA patterns in healthy middle-aged women have found that as many as $74.1 \%$ of women do not follow the PA recommendations in the case of leisure activities. When multiple domains are included in the total PA, $26.6 \%$ of middleaged women do not meet the PA recommendations [24]. There are currently no studies in the Czech Republic that assess the relation between the volume of performed weekly physical activity and body composition in premenopausal women.

Based on the aforementioned findings, the following working hypothesis can be defined: an increasing amount of weekly physical activity of premenopausal women leads to improved body composition parameter values, a lower ratio of body fat and visceral fat, and a higher ratio of fat-free mass. The amount of physical load in active women leads to changes in FFM and BF in lower limbs that are preferentially exposed to load during exercise. Since the literature indicates a protective effect of physical activity on body composition, we set out to test the relationship between the amount of implemented weekly leisure physical activity and the volume of body fat and fat-free mass in full-time employed premenopausal women.

\section{Materials and Methods}

\subsection{Participants}

The study participants included 145 women, aged between 36 and 45 years, who met all the criteria for inclusion in the Healthy Ageing in Industrial Environment StudyProgram 4 (4HAIE). The study participants were recruited via a stratified recruitment 
strategy, with the assistance of a professional marketing and social science research company in the regions of North Moravia and South Bohemia, each with a different influence of external environmental factors due to long-term industrial activity. The input criteria for inclusion in the basic study set were: aged between 18 and 65 years; non-smoking; able to perform normal physical activity including running (i.e., no medical restrictions on physical activity mandated by a physician); residing in the region for the past five years, without any plans to move in the following year; having a smart phone and access to the Internet (Wi-Fi or data). The common exclusion criteria included: acute (in the past six weeks) medical issues (pain, injury, surgery) preventing normal physical activity, other acute illnesses; pregnancy; radiological examination in the past seven days; factors that would exclude a graded exercise test or magnetic resonance examination (such as a pacemaker, radioactive or surgical devices/implants, insulin pump); being menopausal or having strong menstrual irregularities that may indicate early menopause. We introduced a subset from the basic selection for further assessment that respected the regular physical activity of women. The classification criteria were the following: a group of active "runners" (regular running in the last six weeks, at least $10 \mathrm{~km}$ per week) and a group of "inactive" individuals who did not meet the public recommendations on physical activity (i.e., who performed fewer than 150 min of physical activity at moderate or vigorous intensity) were recruited in each region [22]. A detailed protocol of functional and morphological measurements was described in Cipryan et al. [25]. Nine women were excluded due to incomplete data or outlying values, resulting in a sample of $n=136$.

The main objective of the 4HAIE study was to assess the effect of air pollution on health, physical activity, and aging. The study focused on the adult population in two regions of the Czech Republic. The Moravian-Silesian Region is a region with heightened air pollution, and the South Bohemian Region is a control region with relatively low levels of air pollution [22].

\subsection{Procedures}

Participation in the study was voluntary, and all the participants signed informed consent agreements that they received during the initial measurements in the laboratory. Details about the 4HAIE study design, methods, and measurement protocol are available in previous publications. The physiological and anthropometric protocol was presented in the publication by [25]; the behavioral, psychological, and neuroimaging protocol was presented in the publication by [26]; the biomechanical and musculoskeletal protocol was presented in the publication by [27]. The study was approved by the ethics committee of the University of Ostrava (protocol code OU-87674/90-2018 and date of approval 29 November 2018), and was in compliance with the Helsinki Declaration.

\subsection{Physical Activity Assessment}

Physical activity after joining the 4HAIE study was assessed using The Leisure-Time Exercise Questionnaire (LTEQ) [28], administered online via the Qualtrics platform within a longer baseline questionnaire. The wording was modified to reflect leisure-time physical activity (not only physical exercise). The LTEQ is a self-report questionnaire that records the amount of average weekly PA in the previous month at three intensity levels (strenuous, moderate, light). Participants specifically state the weekly frequency and duration of the activity (for activities of a minimum duration of $10 \mathrm{~min}$ ) that they performed in the previous month in their leisure time outside work. The LTEQ score thus reflects the total average level of leisure-time PA (also called Leisure Score Index; LSI), calculated by multiplying the number of reported PA episodes by 3,5, and 9 metabolic equivalents (MET) and adding them up. The questionnaire is considered a valid and reliable instrument for measuring PA in the adult population [29]. The results of the LTEQ questionnaire are presented in Table 1. 
Table 1. Reported level of physical activity under LTEQ.

\begin{tabular}{ccccc}
\hline \multirow{2}{*}{ Variable } & \multicolumn{4}{c}{ Group } \\
\cline { 2 - 5 } & Total $(\boldsymbol{n = 1 3 6 )}$ & T1 $(\boldsymbol{n}=\mathbf{4 7})$ & T2 $(\boldsymbol{n = 4 5 )}$ & T3 $(\boldsymbol{n}=\mathbf{4 4})$ \\
\hline${ }^{*}$ LTEQ-M \pm SD & $41.90 \pm 23.06$ & $18.81 \pm 8.14$ & $40.42 \pm 4.26$ & $68.09 \pm 17.11$ \\
Min & 5 & 5 & 32 & 48 \\
Max & 119 & 30 & 47 & 119 \\
\hline
\end{tabular}

LTEQ-Leisure-time exercise questionnaire, ${ }^{*}$ the values in the table represent LSI before log transformation, $\mathrm{M}$ Mean, SD—standard deviation, Min—minimum values, Max — maximum values, T1—lowest tertile, T2—medium tertile, T3-highest tertile, $n$-frequency.

\subsection{Somatic Measurements}

To ensure standard conditions of measurement, the participants were admitted to the research center $15 \mathrm{~h}$ prior to the measurement (they slept in the sleep laboratory). Measurements started at 8:30 a.m. All measurements were taken in the following order: body height $(\mathrm{BH})$, body mass $(\mathrm{BM})$, body composition. $\mathrm{BH}$ and $\mathrm{BM}$, which are the input parameters for the bone densitometer software, were measured using the InBody BSM 370 stadiometer (Biospace, South Korea). The measured body composition parameters included: body mass (BM), body fat (BF), fat-free mass (FFM), and visceral fat (VF). Furthermore, the segmental distribution of $\mathrm{BM}$ and $\mathrm{BF}$ was measured. To measure body composition, the DXA method was used, with a Hologic QDR Horizon A bone densitometer (Hologic, Waltham, MA, USA). The positions during the measurement and the measured segments were presented in the protocol article [25]. The appendicular index was calculated to assess the risk of the occurrence of sarcopenia [16]. Weight status was assessed with BMI $\left(\mathrm{kg} / \mathrm{m}^{2}\right)$ according to WHO: $\leq 18.49\left(\mathrm{~kg} / \mathrm{m}^{2}\right)$ —underweight, $18.50-24.99\left(\mathrm{~kg} / \mathrm{m}^{2}\right)$ —normal weight, $25.00-29.99\left(\mathrm{~kg} / \mathrm{m}^{2}\right)$-overweight (pre-obesity), 30.00-34.99 $\left(\mathrm{kg} / \mathrm{m}^{2}\right)$-obesity class I, $\geq 35.00\left(\mathrm{~kg} / \mathrm{m}^{2}\right)$ —obesity class II.

\subsection{Statistics Analysis}

For the analysis, the study sample was divided into three groups according to the level of reported leisure-time physical activity (PA) by division into tertiles: (1) lowest tertilelowest PA volume (T1); (2) medium tertile-medium PA volume (T2), (3) highest tertilehigh PA volume (T3). The classification into tertiles was made using log-transformed data in view of abnormal distribution.

One-way ANOVA was used to compare differences in the means of whole-body and segmental analyses. The post hoc test was used to determine statistically significant differences between the groups. The $t$ test was used to analyze the symmetry of BM and $\mathrm{BF}$ distribution in the upper and lower extremities. The level of statistical significance for all used tests was set at $\alpha=0.05$.

Practical significance was verified for values that indicated a statistically significant difference. Practical significance was assessed using the effect of size (ES) by Cohen (Cohen's $d$ ). The $d$ value at the level of 0.2 indicated a minor difference, 0.5 an intermediate difference, and 0.8 a major difference [30]. We considered the value of Cohen's $d \geq 0.5$ to be practically significant.

The statistical processing of the results was performed using IBM SPSS Statistics (Version 24; IBM, Armonk, NY, USA).

\section{Results}

\subsection{Sample Characteristics}

The demographic values of the sample are presented in Table 2. The majority of women were married, highly educated, with an average self-reported economic family standing. 
Table 2. Demographic characteristics of the sample.

\begin{tabular}{|c|c|c|c|c|c|}
\hline \multicolumn{2}{|c|}{ Variable } & $\begin{array}{c}\text { Total } \\
(n=136)\end{array}$ & $\begin{array}{c}\text { T1 } \\
(n=47)\end{array}$ & $\begin{array}{c}\text { T2 } \\
(n=45)\end{array}$ & $\begin{array}{c}\text { T3 } \\
(n=44)\end{array}$ \\
\hline \multicolumn{2}{|c|}{ Age (years) } & $\mathrm{M} \pm \mathrm{SD}$ & $\mathrm{M} \pm \mathrm{SD}$ & $\mathrm{M} \pm \mathrm{SD}$ & $\mathrm{M} \pm \mathrm{SD}$ \\
\hline \multirow{6}{*}{ Marital status } & & $n(\%)$ & $n(\%)$ & $n(\%)$ & $n(\%)$ \\
\hline & Single & $10(7 \%)$ & $7(15 \%)$ & $2(4 \%)$ & $1(2 \%)$ \\
\hline & Married & $90(66 \%)$ & $31(66 \%)$ & $26(58 \%)$ & $33(75 \%)$ \\
\hline & Cohabitation & $13(10 \%)$ & $4(9 \%)$ & $8(18 \%)$ & $1(2 \%)$ \\
\hline & Divorced & $22(16 \%)$ & $5(11 \%)$ & $8(18 \%)$ & $9(21 \%)$ \\
\hline & Widow & $1(0.7 \%)$ & $0(0 \%)$ & $1(2 \%)$ & $0(0 \%)$ \\
\hline \multirow{4}{*}{ Education } & $\begin{array}{l}\text { Trained, high school without } \\
\text { school leaving certificate }\end{array}$ & $8(6 \%)$ & $2(4 \%)$ & $2(4 \%)$ & $4(9 \%)$ \\
\hline & $\begin{array}{l}\text { High school with school } \\
\text { leaving certificate }\end{array}$ & $56(41 \%)$ & $20(43 \%)$ & $21(47 \%)$ & $15(34 \%)$ \\
\hline & Higher vocational & $7(5 \%)$ & $0(0 \%)$ & $4(9 \%)$ & $3(7 \%)$ \\
\hline & University & $65(48 \%)$ & $25(53 \%)$ & $18(40 \%)$ & $22(50 \%)$ \\
\hline \multirow{3}{*}{$\begin{array}{l}\text { Economic situation of the family } \\
\text { (as assessed by the participants) }\end{array}$} & Below average & $4(3 \%)$ & $1(2 \%)$ & $2(4 \%)$ & $1(2 \%)$ \\
\hline & Average & $110(81 \%)$ & $37(79 \%)$ & $35(78 \%)$ & $38(91 \%)$ \\
\hline & Above average & $22(16 \%)$ & $9(19 \%)$ & $8(18 \%)$ & $5(7 \%)$ \\
\hline
\end{tabular}

T1-women in the lowest tertile, T2-women in the medium tertile, T3-women in the highest tertile, $n$-frequency in individual tertiles, $\mathrm{M}-$ mean, SD—standard deviation.

In terms of sociodemographic differences across the tertiles, there were no differences in age between the T1, T2, and T3 groups. However, the individual groups of women differed in marital status, education, or the economic situation of the family. T1 had the most single women; T3 had the most married and divorced women; T2 had the most women living in cohabitation. T3 had the most women without a high school education certificate; T2 had the most women with a high school certificate and higher vocational education; T1 had the most women with a university education. T2 had the most women who assessed the economic situation in their families as below average; T3 women reported an average economic situation, and T1 women were above average economically.

\subsection{Whole-Body Analysis}

Table 3 presents the mean values of the whole-body analysis of body composition. The comparison of differences in the mean values of the whole-body analysis between the monitored groups is presented in Table 4. The whole-body analysis also included the assessment of weight status by BMI (Table 5).

Table 3. Mean values of whole-body analysis of body composition in monitored women in the individual tertiles and differences determined by ANOVA $\left({ }^{*}\right.$ statistically significant difference, ${ }^{\mathrm{NS}}$ no significant difference).

\begin{tabular}{|c|c|c|c|}
\hline Parameters & $\begin{array}{c}\mathrm{T} 1(n=47) \\
\mathrm{M} \pm \mathrm{SD}\end{array}$ & $\begin{array}{c}\mathrm{T} 2(n=45) \\
\mathrm{M} \pm \mathrm{SD}\end{array}$ & $\begin{array}{c}\mathrm{T} 3(n=44) \\
\mathrm{M} \pm \mathrm{SD}\end{array}$ \\
\hline $\mathrm{BH}(\mathrm{cm}){ }^{\mathrm{NS}}$ & $167.30 \pm 6.23$ & $168.85 \pm 5.78$ & $168.29 \pm 6.39$ \\
\hline $\mathrm{BM}(\mathrm{kg}) *$ & $72.38 \pm 13.44$ & $66.28 \pm 10.55$ & $66.39 \pm 9.20$ \\
\hline $\mathrm{BMI}(\mathrm{kg} / \mathrm{m} 2)$ * & $25.29 \pm 4.59$ & $22.60 \pm 3.29$ & $22.76 \pm 2.60$ \\
\hline $\mathrm{BF}(\mathrm{kg}) *$ & $27.22 \pm 8.88$ & $21.24 \pm 6.68$ & $20.80 \pm 5.51$ \\
\hline $\mathrm{BF}(\%) *$ & $36.81 \pm 5.73$ & $31.39 \pm 5.28$ & $30.92 \pm 4.52$ \\
\hline FFM (kg) NS & $45.16 \pm 5.72$ & $45.04 \pm 4.92$ & $45.59 \pm 4.76$ \\
\hline $\operatorname{FFM}(\%) *$ & $63.19 \pm 5.73$ & $68.61 \pm 5.28$ & $69.08 \pm 4.52$ \\
\hline VFA $(\mathrm{cm} 2) *$ & $70.35 \pm 36.21$ & $52.86 \pm 31.79$ & $49.64 \pm 18.31$ \\
\hline App. index $(\mathrm{kg} / \mathrm{m} 2)^{\mathrm{NS}}$ & $6.53 \pm 0.79$ & $6.45 \pm 0.60$ & $6.60 \pm 0.57$ \\
\hline
\end{tabular}

BH—body height, BM-body mass, BMI—body mass index, BF-body fat, FFM-fat-free mass, VFA—visceral fat area, App. index-Appendicular fat-free mass/body height $2, \mathrm{M}-\mathrm{mean}, \mathrm{SD}$ - standard deviation, $n-$ frequency. 
Table 4. Results of the post hoc tests of the whole-body analysis of the monitored women.

\begin{tabular}{|c|c|c|c|c|c|c|}
\hline \multirow{2}{*}{ Parameters } & \multicolumn{2}{|c|}{ T1 vs. T2 } & \multicolumn{2}{|c|}{ T1 vs. T3 } & \multicolumn{2}{|c|}{$\mathrm{T} 2$ vs. $\mathrm{T} 3$} \\
\hline & diff & $d$ & diff & $d$ & diff & $d$ \\
\hline $\mathrm{BM}(\mathrm{kg})$ & $+6.10 *$ & 0.50 & $+5.99 *$ & 0.52 & $+0.23^{\mathrm{ns}}$ & - \\
\hline BMI $\left(\mathrm{kg} / \mathrm{m}^{2}\right)$ & $+2.69 * *$ & 0.67 & $+2.53^{* *}$ & 0.67 & $-0.07^{\mathrm{ns}}$ & - \\
\hline $\mathrm{BF}(\mathrm{kg})$ & $+5.98 * * *$ & 0.76 & $+6.42 * * *$ & 0.86 & $+0.58^{\mathrm{ns}}$ & - \\
\hline $\mathrm{BF}(\%)$ & $+5.42 * * *$ & 0.98 & $+5.89 * * *$ & 1.14 & $+0.54^{\mathrm{ns}}$ & - \\
\hline FFM (\%) & $-5.42^{* * *}$ & 0.98 & $-5.89 * * *$ & 1.14 & $-0.54^{\mathrm{ns}}$ & - \\
\hline VFA $\left(\mathrm{cm}^{2}\right)$ & $+17.49 *$ & 0.51 & $+20.71^{* *}$ & 0.71 & $+3.8^{\mathrm{ns}}$ & - \\
\hline
\end{tabular}

Table 5. Weight status assessment by BMI $\left(\mathrm{kg} / \mathrm{m}^{2}\right)$ according to WHO.

\begin{tabular}{cccccc}
\hline Group & $\begin{array}{c}\leq \mathbf{1 8 : 4 9} \\
\boldsymbol{n} \mathbf{( \% )}\end{array}$ & $\begin{array}{c}\mathbf{1 8 . 5 0 - 2 4 . 9 9} \\
\boldsymbol{n ( \% )}\end{array}$ & $\begin{array}{c}\mathbf{2 5 . 0 0 - 2 9 . 9 9} \\
\boldsymbol{n} \mathbf{( \% )}\end{array}$ & $\begin{array}{c}\mathbf{3 0 . 0 0 - 3 4 . 9 9} \\
\boldsymbol{n} \mathbf{( \% )}\end{array}$ & $\begin{array}{c}\geq \mathbf{3 5 . 0 0} \\
\boldsymbol{n} \mathbf{( \% )}\end{array}$ \\
\hline T1 $(n=47)$ & & $26(55.3)$ & $13(27.7)$ & $6(12.8)$ & $2(4.2)$ \\
T2 $(n=45)$ & $3(6.7)$ & $34(75.5)$ & $7(15.6)$ & $1(2.2)$ & \\
T3 $(n=44)$ & & $36(81.8)$ & $8(18.2)$ & & \\
\hline -frequency & & &
\end{tabular}

Statistically significant differences were detected in the parameters of BM, BMI, BF, FFM (\%), and VFA. The post hoc test was performed with these parameters, and the results are presented in Table 4.

Table 4 presents only the parameters that the ANOVA showed to be statistically significant (Table 3). The average values of all monitored parameters in T1 women presented in Table 4 differed significantly when compared with the mean values of T2 and T3 women. Moreover, practical significance was proven in all parameters $(d \geq 0.5)$. When compared with T2 and T3 women, T1 women had a higher body weight, given the higher value of body fat, which was also manifested in their higher fat ratio percentage and lower fat-free mass ratio percentage. $\mathrm{T} 1$ women also had a significantly higher amount of visceral fat.

When comparing the mean values of T2 and T3 women, we found higher body mass, body fat, and visceral fat in $\mathrm{T} 2$ women, and lower values of the fat-free mass ratio percentage. However, the differences between T2 and T3 women were not statistically significant.

We assessed the weight status based on a detailed BMI analysis of the individual participants and their classification in BMI assessment categories according to the World Health Organization [31] (Table 5).

The differences found in body height between the groups of women were not significant. T1 women had a significantly higher body mass than T2 and T3 women (Tables 3 and 4). This significant difference was reflected in the significantly higher mean value of BMI in $\mathrm{T} 1$ women when compared with the mean values of women in T2 and T3 (Table 4). The differences in BMI were also apparent across the tertiles. Normal weight was found in $55.3 \%$ of T1 women; overweight and obesity in $44.7 \%$. A total of $17 \%$ of the women in $\mathrm{T} 1$ were obese.

When comparing T2 and T3 women, although the differences in mean values were statistically insignificant (Table 4), there were slight differences in the weight status assessment. T3 showed a higher number of women in the normal weight category $(81.8 \%)$ and no woman was in the obese category. In the T2 group, there was one woman in the obese category $(2.2 \%)$ and three women in the underweight category $(6.7 \%)$. Those differences were reflected in a larger dispersion of values in T2 women than in T3 women (Table 3).

\subsection{Segmental Analysis}

The mean of the segmental body mass and body fat is presented in Figure 1. 
A.
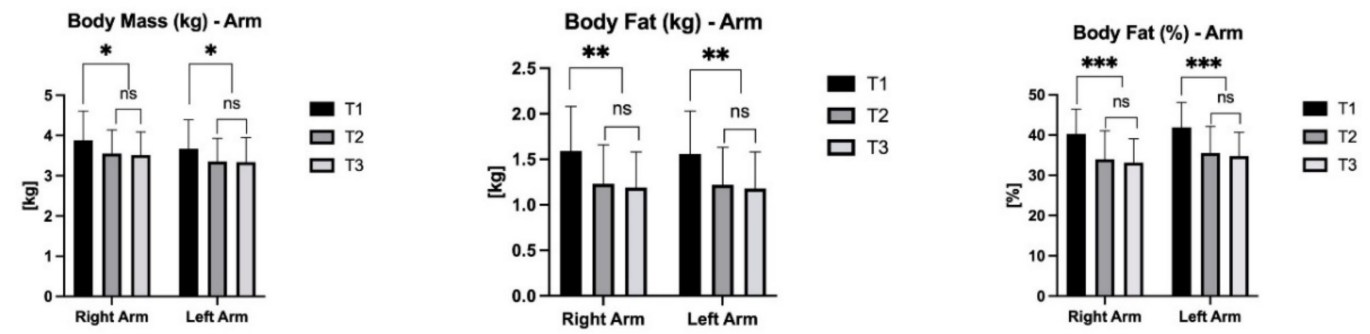

B.
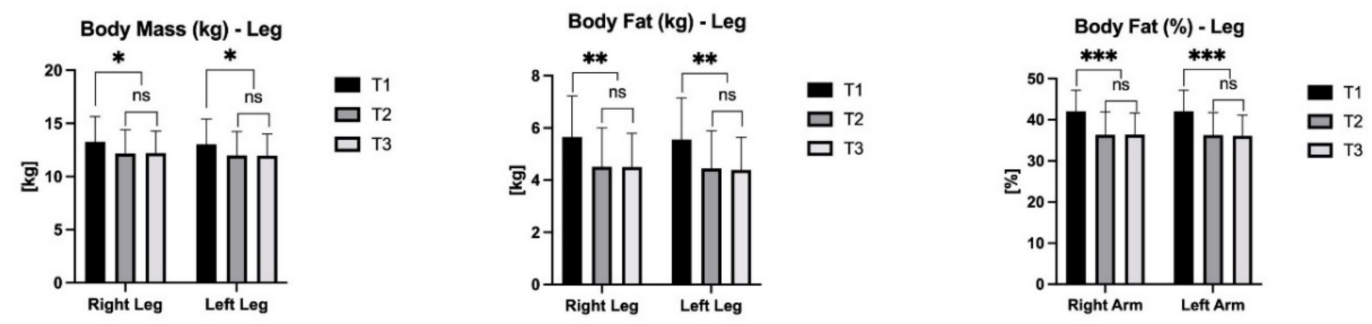

C.
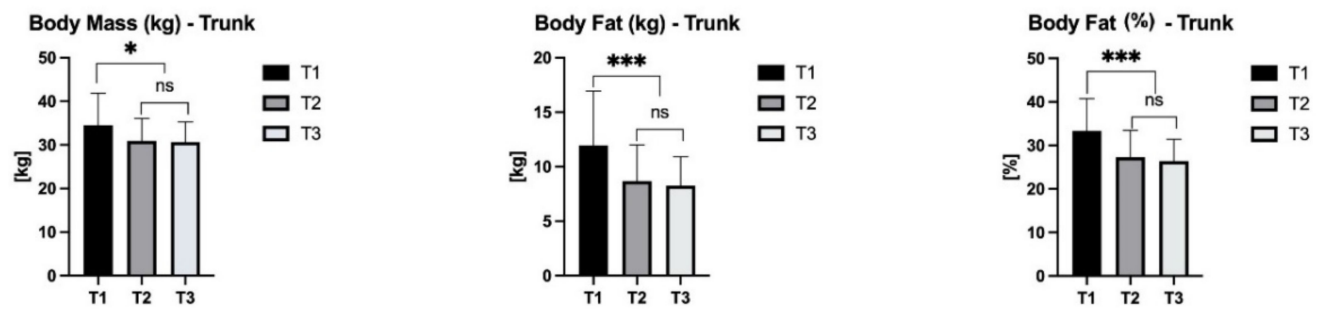

Figure 1. Mean values of segmental body mass and body fat distribution in the monitored women. (A) Distribution of BM and BF in upper limbs, (B) Distribution of BM and BF in lower limbs, (C) Distribution of BM and BF in the trunk. ${ }^{\mathrm{ns}}$ not significant, ${ }^{*} p<0.05,{ }^{* *} p<0.01,{ }^{* * *} p<0.001$.

\subsubsection{Limb Symmetry Assessment}

The segmental analysis of symmetry was assessed based on the body mass and body fat ratio in the upper and lower limbs (Figure 1A,B). The results of the analysis showed that practically no meaningful asymmetries were found in the upper and lower limbs of women in all monitored groups, although some statistically significant differences were found $(p<0.05-0.001)$.

\subsubsection{Segment Assessment}

The differences in the BM and BF segmental analysis between the monitored groups of women are presented in Figure 1. The analysis of the individual body segments (arm, leg, trunk) suggested that the segment weight, as well as the BF ratio in the T1 group with the lowest physical activity, were higher than in T2 and T3 (Figure 1). The differences were both statistically significant and practically meaningful $(d \geq 0.5)$. The comparison of the mean values of body mass and body fat in limbs and trunk between T2 and T3 women showed that T2 women had a higher segment weight, as well as a higher BF ratio in the upper limbs and trunk; however, the differences were not statistically significant. The found segmental differences mirrored the differences in total weight (as a percentage, as well as in total).

\section{Discussion}

The essential outcome of the assessment of total body mass in the monitored women was the finding that women with the lowest volume of leisure-time PA (T1) had the least favorable body composition. Although the occurrence of overweight was lower and obesity was higher in these women than the rates reported by the WHO [2], the values were within the expected ranges of values reported in the Czech Republic. Eurostat data showed the prevalence of overweight women at $30.1 \%$ and obesity at $18.3 \%$ [32]; similar values were 
also reported by the Czech Statistical Office [33]. The BMI values determined in women with a medium (T2) and a high volume of PA (T3) were considerably lower.

The considerably lower body fat ratio found in women with a medium (T2) and a high volume of PA (T3) when compared with the values of the women with the lowest volume of PA (T1) corresponded to the differences in their weight status. The differences found in body fat were not only significant, but also considerably higher than the stated error of measurement in body fat assessment using the bone densitometer [34]. The lower $\mathrm{BF}$ ratio in $\mathrm{T} 2$ and $\mathrm{T} 3$ women was also related to the higher fat-free mass ratio, which was suggested by the weight differences. In general, lower body fat values and higher fat-free mass values reduce the risk of cardiac metabolic diseases [35,36]. Based on our results, we can conclude that the aforesaid also applies to the women in the study with a medium (T2) and a high volume of PA (T3). This is important especially in view of the fact that BF increases and FFM decreases in women as they age [37]. Distinct changes in women's body composition occur in relation to menopause [3]. The results of a study based on the data from the Study of Women's Health Across the Nation (SWAN) showed that there is a considerable increase in $\mathrm{BF}$, accompanied by a decrease in FFM about 2 years prior to the final menstrual period (FMP) and these changes slow down about 1.5 years after the FMP. After this period, the aforementioned changes (BF increase and FFM decrease) occur evenly [3].

To confirm the total weight status based on BMI, we also compared the percentage ratios of body mass and body fat weight in the whole-body and segmental analyses between the groups of monitored women. The ratio of total weight and body fat weight was preserved even in the ratio in the limb segments (upper and lower). Differences in the ratios of total weight and body fat weight in the trunk were higher than in the limbs between $\mathrm{T} 1$ and $\mathrm{T} 2$, and between $\mathrm{T} 1$ and $\mathrm{T} 3$. The only difference in the ratio in the trunk and in the limbs between T2 and T3 was found in the body fat weight. The differences in the visceral fat values, expressed as an area in this study (VFA), were caused by the different values for the amount of fat in the trunk. The significantly higher VFA values in women with the lowest volume of PA (T1) indicated an increased risk of overweight, obesity, cardiovascular and metabolic complications, as shown by studies confirming links between visceral fat, cardiovascular complications, obesity, and type 2 diabetes [38-40]. The risk of visceral fat is determined by its higher metabolic activity than the activity of subcutaneous fat [41].

Overweight and obesity usually act as demotivational factors for regular physical activity. The evidence for this lies in the increasing number of people who are overweight or obese [2]. Muscles not exposed to load have a clear tendency to atrophy, the muscle cross-section decreases, and sarcopenia starts to develop, which can be assessed using the appendicular index, based on the DXA measurement. This process develops considerably from the onset of middle age and becomes more significant with increasing age [7]. Another consequence is the reduced ability of the organism to produce strength, which may influence the independence and self-care of individuals, together with a reduction in regeneration after workload. Our appendicular index results did not show any significant differences in the mean values between the individual groups of women. The mean value of the appendicular index did not drop below its limit value of $5.67 \mathrm{~kg} / \mathrm{m}^{2}$ in any of the monitored groups of women [16]. However, we did find differences in results during the detailed analysis. We determined the index value $\leq 5.67 \mathrm{~kg} / \mathrm{m}^{2}$ in six women $(12.66 \%)$ with the lowest volume of PA (T1), in four women (8.89\%) with the medium volume of PA (T2), and none in the group with the highest volume of PA (T3). Therefore, less physically active women are potentially at a higher risk of sarcopenia during their aging.

We did not find any significant differences in the values of body fat and fat-free mass between women with the medium (T2) and the highest volumes of PA (T3). Nevertheless, the differences found were higher than the average typical error of measurement (TE) and upper limit confidence interval [34]. The results thus indicated that even a medium level of weekly PA has a considerable impact on the distribution and size of the adipose 
tissue, and, thus, on cardiac metabolic risk, as well as the risk of sarcopenia assessed by the appendicular index.

The higher volumes of performed PA in the T2 and T3 groups of women were determined by the preference for running in these groups. These women met the inclusion criteria for runners in Program 4HAIE. We can thus presume that running has a positive effect on the risk of obesity and sarcopenia in premenopausal women. This presumption was also confirmed by the results of studies on the impact of running on the state of health. Research has suggested that running has a positive effect on the cardiovascular, metabolic, musculoskeletal, and neurocognitive system, reducing premature mortality in runners by 25-40\%, and increasing their life expectancy by up to three years when compared with nonrunners [42,43]. A similar effect can be achieved by activities that put a load on large muscle groups.

Our presumption of a relationship between the volume of implemented weekly leisuretime physical activity and the quantity of body fat and fat-free mass in premenopausal women was only confirmed for body fat. Furthermore, the study showed that the volume of performed weekly PA was essential in the reduction of body fat in full-time employed premenopausal women, but it did not affect fat-free mass and, thus, the quantity of muscle tissue. The question that needs to be answered is, 'what is the minimum amount of physical activity that induces significant changes?', which is important for women at this age. For example, the results of one systematic review stated that no significant changes in the values of visceral fat (VF) were found at a volume of exercise of around 150 min per week, which is the current, generally recommended volume. The effective amount of exercise to lower VF in this review was 30-60 min of high-intensity interval training three times a week [44].

The aforementioned results and the data that we collected only enabled us to partially accept the set working hypothesis. Only the values of the T1 women differed significantly (lowest volume of PA). No significant differences were found between the T2 (medium volume of PA) and T3 (highest volume of PA) women.

The effects of energy metabolism as well as adipose and muscle tissue metabolism count among other factors that may affect the results obtained by us. The way of covering energy requirements, which varies depending on the current state of health, intensity of strain, current level of fitness and age, is the basic metabolic function. This is also affected by the availability of nutrients, which are primarily used to ensure movement. People with higher physical activity also have a higher positive nitrogen balance, with a consequent effect on the volume of muscle tissue. Movement control (the technique of carrying out movement), including hormonal control, constitutes another variable that affects energy metabolism. Increased weight, which affects the onset of fatigue, is an important factor as well. Therefore, weight reduction is vital for rehabilitation. Weight reduction is also important in view of the fact that obesity gives rise to hypertrophy, hyperplasia and inflammatory activation of adipose tissue, leading to the accumulation of macrophages and lymphocytes that produce proinflammatory cytokines [4]. These changes subsequently not only lead to a negative effect on muscle tissue, but also have a significant effect on the development of insulin resistance [45]. We consider primary and secondary prevention, as well as non-pharmacological interventions, to be of key importance. The overall physical regime, spontaneous and controlled physical activities, achieved education and the nature of one's work, play a substantial role. More detailed information and outcomes could be provided by multiple regression, where the components of body composition would be the dependent variable, while the types of physical activity, its intensity, weight status, education and the nature of work activity of the monitored individuals would be the independent variables. Year-round (long-term) monitoring is required to eliminate any seasonal fluctuations in physical activity, diet and related changes in body composition components. Furthermore, the object of the physical activity monitoring should be increased as a self-reporting check. The findings from monitoring ontogenetic changes would also be an important contribution. 


\section{Limitations}

This study has several limitations. The first limitation is the fact that it was a crosssectional study that indicated a relation between the monitored variables, but did not provide evidence of causal relations. The study also did not allow for an unambiguous assessment of the effect of age and season of the year. These facts limit the generalization of results. The second limitation is the composition of the monitored groups. The monitored groups of women differed in demographic characteristics. At the same time, all groups had a significantly higher ratio of women with university education than was the national average, which is $30 \%$ of women in the 35-44 year age category [46]. The third limitation involves not having assessed the influence of diet or caloric intake. We are aware that diet is an important factor that may influence body composition, namely, its fat component. However, the 4HAIE project protocol did not include a validated assessment of diet. The fourth limitation is the assessment of physical activity via self-report, which is subject to various forms of distortion. The 4HAIE study included an objective assessment of physical activity via Fitbit Charge 3 monitors. Subsequent analysis of the entire 4HAIE cohort will include this parameter. Another limitation that prevents the generalization of results is the size of the group.

\section{Conclusions}

The study results indicated that the volume of weekly leisure-time physical activity is reflected in the body composition of premenopausal women. The increased volume of performed weekly physical activity in women led to lower values of body mass and body fat ratio and a higher fat-free mass ratio without a significant increase in the total weight. The reduced body fat was most obvious in the trunk. Obesity contributes to the development of sarcopenia as early as middle age, which may affect the pursuit of physical activities, as well as independence and self-care, together with reduced regeneration after workload.

An increase in physical activity above the recommended weekly amount [22] has an insignificant effect on body composition. The physical activity of premenopausal women that meets the recommended weekly volume should lead, above all, to a reduction in the body ratio in the trunk, without a significant increase in the weight of fat-free mass. This suggests supplementing physical activity with activities aimed at maintaining or increasing muscle mass (e.g., weight or resistance training).

Although the majority of the physical activities comprised lower limb activities, this training did not affect the body composition of the lower limbs. For significant changes in lean mass and muscle mass and reduction in the amount of BF, it will be necessary to include resistance training involving the relevant limbs in movement training.

Author Contributions: Conceptualization, P.K., M.B., S.E. and D.J.; methodology, P.K., S.E. and D.J.; validation, P.K. and S.E.; formal analysis, P.K., S.E. and M.K.; investigation, P.K. and S.E.; resources, D.J.; data curation, P.K. and S.E.; writing—original draft preparation, P.K., M.B., S.E., V.B., D.J. and M.K.; writing-review and editing, P.K., M.B., S.E., V.B., D.J. and M.K.; visualization, P.K. and M.K.; supervision, D.J.; project administration, D.J.; funding acquisition, D.J. All authors have read and agreed to the published version of the manuscript.

Funding: This research was funded by Program 4 HAIE-Healthy Aging in Industrial Environment (grant number: CZ.02.1.01/0.0/0.0/16_019/0000798).

Institutional Review Board Statement: The study was approved by the ethics committee of the University of Ostrava (protocol code OU-87674/90-2018 and date of approval 29 November 2018) and it was in compliance with the Helsinki Declaration.

Informed Consent Statement: Informed consent was obtained from all subjects involved in the study.

Data Availability Statement: Available data from Program 4 HAIE can be found at https:/ / www. 4haie.cz/data/ (accessed on 1 May 2021) and results and publications from Program 4 HAIE can be found at https:/ / www.4haie.cz/publikace/ (accessed on 1 May 2020). 
Conflicts of Interest: The authors declare no conflict of interest.

\section{References}

1. Mayo, X.; Liguori, G.; Iglesias-Soler, E.; Copeland, R.J.; Clavel San Emeterio, I.; Lowe, A.; Del Villar, F.; Jimenez, A. The Active Living Gender's Gap Challenge: 2013-2017 Eurobarometers Physical Inactivity Data Show Constant Higher Prevalence in Women with No Progress towards Global Reduction Goals. BMC Public Health 2019, 19, 1-10. [CrossRef]

2. World Health Organisation. Obesity and Overweight. Available online: https://www.who.int/news-room/fact-sheets/detail/ obesity-and-overweight (accessed on 20 April 2021).

3. Greendale, G.A.; Sternfeld, B.; Huang, M.H.; Han, W.; Karvonen-Gutierrez, C.; Ruppert, K.; Cauley, J.A.; Finkelstein, J.S.; Jiang, S.F.; Karlamangla, A.S. Changes in Body Composition and Weight during the Menopause Transition. JCI Insight 2019, 4, 1-14. [CrossRef] [PubMed]

4. Kalinkovich, A.; Livshits, G. Sarcopenic Obesity or Obese Sarcopenia: A Cross Talk between Age-Associated Adipose Tissue and Skeletal Muscle Inflammation as a Main Mechanism of the Pathogenesis. Ageing Res. Rev. 2017, 35, 200-221. [CrossRef] [PubMed]

5. Lynch, G.M.; Murphy, C.H.; Castro, E.D.M.; Roche, H.M. Inflammation and Metabolism: The Role of Adiposity in Sarcopenic Obesity. Proc. Nutr. Soc. 2020, 79, 435-447. [CrossRef]

6. Hong, S.-H.; Choi, K.M. Molecular Sciences Sarcopenic Obesity, Insulin Resistance, and Their Implications in Cardiovascular and Metabolic Consequences. Int. J. Mol. Sci. 2020, 21, 494. [CrossRef] [PubMed]

7. Bautmans, I.; Puyvelde, K.; Mets, T. Sarcopenia and Functional Decline: Pathophysiology, Prevention and Therapy. Acta Clin. Belg. 2009, 64, 303-316. [CrossRef] [PubMed]

8. Cruz-Jentoft, A.J.; Bahat, G.; Bauer, J.; Boirie, Y.; Bruyère, O.; Cederholm, T.; Cooper, C.; Landi, F.; Rolland, Y.; Sayer, A.A.; et al. Sarcopenia: Revised European Consensus on Definition and Diagnosis. Age Ageing 2019, 48, 16-31. [CrossRef]

9. Delmonico, M.J.; Harris, T.B.; Lee, J.S.; Visser, M.; Nevitt, M.; Kritchevsky, S.B.; Tylavsky, F.A.; Newman, A.B. Alternative Definitions of Sarcopenia, Lower Extremity Performance, and Functional Impairment with Aging in Older Men and Women. J. Am. Geriatr. Soc. 2007, 55, 769-774. [CrossRef]

10. Lauretani, F.; Russo, C.R.; Bandinelli, S.; Bartali, B.; Cavazzini, C.; Di Iorio, A.; Corsi, A.M.; Rantanen, T.; Guralnik, J.M.; Ferrucci, L. Age-Associated Changes in Skeletal Muscles and Their Effect on Mobility: An Operational Diagnosis of Sarcopenia. J. Appl. Physiol. 2003, 95, 1851-1860. [CrossRef]

11. Nascimento, C.M.; Ingles, M.; Salvador-Pascual, A.; Cominetti, M.R.; Gomez-Cabrera, M.C.; Viña, J. Sarcopenia, Frailty and Their Prevention by Exercise. Free Radic. Biol. Med. 2019, 132, 42-49. [CrossRef]

12. Shafiee, G.; Keshtkar, A.; Soltani, A.; Ahadi, Z.; Larijani, B.; Heshmat, R. Prevalence of Sarcopenia in the World: A Systematic Review and Meta- Analysis of General Population Studies. J. Diabetes Metab. Disord. 2017, 16, 1-10. [CrossRef] [PubMed]

13. Bijlsma, A.Y.; Meskers, C.G.M.; Ling, C.H.Y.; Narici, M.; Kurrle, S.E.; Cameron, I.D.; Westendorp, R.G.J.; Maier, A.B. Defining Sarcopenia: The Impact of Different Diagnostic Criteria on the Prevalence of Sarcopenia in a Large Middle Aged Cohort. Age (Omaha) 2013, 35, 871-881. [CrossRef] [PubMed]

14. Isabel Filippin, L.; Nunes de Oliveira Teixeira, V.; Pilz Monteiro da Silva, M.; Miraglia, F.; Silva da Silva, F. Sarcopenia: A Predictor of Mortality and the Need for Early Diagnosis and Intervention. Aging Clin. Exp. Res. 2015, 27, 249-254. [CrossRef] [PubMed]

15. Theou, O.; Stathokostas, L.; Roland, K.P.; Jakobi, J.M.; Patterson, C.; Vandervoort, A.A.; Jones, G.R. The Effectiveness of Exercise Interventions for the Management of Frailty: A Systematic Review. J. Aging Res. 2011, 2011. [CrossRef] [PubMed]

16. Fielding, R.A.; Vellas, B.; Evans, W.J.; Bhasin, S.; Morley, J.E.; Newman, A.B.; Abellan van Kan, G.; Andrieu, S.; Bauer, J.; Breuille, D.; et al. Sarcopenia: An Undiagnosed Condition in Older Adults. Current Consensus Definition: Prevalence, Etiology, and Consequences. International Working Group on Sarcopenia. J. Am. Med. Dir. Assoc. 2011, 12, 249-256. [CrossRef] [PubMed]

17. Archer, E.; Blair, S.N. Physical Activity and the Prevention of Cardiovascular Disease: From Evolution to Epidemiology. Prog. Cardiovasc. Dis. 2011, 53, 387-396. [CrossRef]

18. Ng, S.W.; Popkin, B. Time Use and Physical Activity: A Shift Awa; Frommovement across the Globe. Obes. Rev. 2013, 13, 659-680. [CrossRef] [PubMed]

19. O'Keefe, J.H.; Vogel, R.; Lavie, C.J.; Cordain, L. Exercise Like a Hunter-Gatherer: A Prescription for Organic Physical Fitness. Prog. Cardiovasc. Dis. 2011, 53, 471-479. [CrossRef] [PubMed]

20. Fennell, C.; Peroutky, K.; Glickamn, E.L. Effects of Supervised Training Compared to Unsupervised Training on Physical Activity, Muscular Endurance, and Cardiovascular Parameters. MOJ Orthop. Rheumatol. 2016, 5, 1-7. [CrossRef]

21. Dwyer, T.; Hosmer, D.; Hosmer, T.; Venn, A.J.; Blizzard, C.L.; Granger, R.H.; Cochrane, J.A.; Blair, S.N.; Shaw, J.E.; Zimmet, P.Z.; et al. The Inverse Relationship between Number of Steps per Day and Obesity in a Population-Based Sample-the AusDiab Study. Int. J. Obes. 2007, 31, 797-804. [CrossRef]

22. World Health Organisation. WHO Guidelines on Physical Activity and Sedentary Behaviour, Web Annex, Evidence Profiles; WHO: Geneva, Switzerland, 2020; ISBN 978-92-4-001511-1.

23. Guthold, R.; Stevens, G.A.; Riley, L.M.; Bull, F.C. Worldwide Trends in Insufficient Physical Activity from 2001 to 2016 : A Pooled Analysis of 358 Population-Based Surveys with 1.9 Million Participants. Lancet Glob. Health 2018, 6, e1077-e1086. [CrossRef]

24. Middlekauff, M.; Lee, W.; Egger, M.J.; Nygaard, I.E.; Shaw, J.M. Physical Activity Patterns in Healthy Middle-Aged Women. J. Women Aging 2016, 28, 469-476. [CrossRef] [PubMed] 
25. Cipryan, L.; Kutac, P.; Dostal, T.; Zimmermann, M.; Krajcigr, M.; Jandackova, V.; Sram, R.; Jandacka, D.; Hofmann, P. Regular Running in an Air-Polluted Environment: Physiological and Anthropometric Protocol for a Prospective Cohort Study (Healthy Aging in Industrial Environment Study-Program 4). BMJ Open 2020, 10, 1-8. [CrossRef] [PubMed]

26. Elavsky, S.; Jandačková, V.; Knapová, L.; Vašendová, V.; Sebera, M.; Kaštovská, B.; Blaschová, D.; Kühnová, J.; Cimler, R.; Vilímek, D.; et al. Physical Activity in an Air-Polluted Environment: Behavioral, Psychological and Neuroimaging Protocol for a Prospective Cohort Study (Healthy Aging in Industrial Environment Study-Program 4). BMC Public Health 2021, $21,1-14$. [CrossRef] [PubMed]

27. Jandacka, D.; Uchytil, J.; Zahradnik, D.; Farana, R.; Vilimek, D.; Skypala, J.; Urbaczka, J.; Plesek, J.; Motyka, A.; Blaschova, D.; et al. Running and Physical Activity in an Air-Polluted Environment: The Biomechanical and Musculoskeletal Protocol for a Prospective Cohort Study 4HAIE (Healthy Aging in Industrial Environment-Program 4). Int. J. Environ. Res. Public Health 2020, 17, 9142. [CrossRef]

28. Godin, G.; Shephard, R. A Simple Method to Assess Exercise Behavior in the Community. Can. J. Appl. Sport Sci. 1985, 10, 141-146. [PubMed]

29. Godin, G.; Jobin, J.; Bouillon, J. Assessment of Leisure-Time Exercise Behavior by Selfreport: A Concurrent Validity Study. Can. J. Public Health 1986, 77, 359-362. [PubMed]

30. Cohen, J. Statistical Power Analysis for the Behavioral Sciences; Lawrence Erlbaum Associates: Mahwah, NJ, USA, 1988; ISBN 0-12-179060-6.

31. World Health Organisation. Obesity: Preventing and Managing the Global Epidemic: Report of a WHO Consultation; WHO: Geneva, Switzerland, 2000; ISBN 92-4-120894-5.

32. Eurostat. Body Mass Index (BMI) by Sex, Age and Country of Citizenship. Available online: https:/ / ec.europa.eu/eurostat/ databrowser/view/HLTH_EHIS_BM1C_custom_763770/default/table?lang=en (accessed on 20 April 2021).

33. Czech Statistical Office. How Are the People with Poverty, Obesity or Sporting? Available online: https://www.czso.cz/csu/ stoletistatistiky/jak-jsou-na-tom-cesi-s-chudobou-obezitou-ci-sportovanim (accessed on 25 April 2021).

34. Kutáč, P.; Bunc, V.; Sigmund, M. Whole-Body Dual-Energy X-Ray Absorptiometry Demonstrates Better Reliability than Segmental Body Composition Analysis in College-Aged Students. PLoS ONE 2019, 14, 1-15. [CrossRef]

35. Liberato, S.C.; Maple-Brown, L.; Bressan, J.; Hills, A.P. The Relationships between Body Composition and Cardiovascular Risk Factors in Young Australian Men. Nutr. J. 2013, 12, 1-10. [CrossRef]

36. Miranda, V.P.N.; Dos Santos Amorim, P.R.; Bastos, R.R.; Canabrava, K.L.R.; Júnior, M.V.M.; Faria, F.R.; Do Carmo Castro Franceschini, S.; Do Carmo Gouveia Peluzio, M.; Priore, S.E. Association of Lifestyle and Body Composition on Risk Factors of Cardiometabolic Diseases and Biomarkers in Female Adolescents. Mediat. Inflamm. 2020, 2020. [CrossRef]

37. Gába, A.; Přidalová, M. Age-Related Changes in Body Composition in a Sample of Czech Women Aged 18-89 Years: A CrossSectional Study. Eur. J. Nutr. 2014, 53, 167-176. [CrossRef] [PubMed]

38. Haberka, M.; Stolarz-Skrzypek, K.; Biedroń, M.; Szóstak-Janiak, K.; Partyka, M.; Olszanecka-Glinianowicz, M.; Gasior, Z. Obesity, Visceral Fat, and Hypertension-Related Complications. Metab. Syndr. Relat. Disord. 2018, 16, 521-529. [CrossRef] [PubMed]

39. Van Gaal, L.F.; Mertens, I.L.; De Block, C.E. Mechanisms Linking Obesity with Cardiovascular Disease. Nature 2006, 444, 875-880. [CrossRef]

40. Verboven, K.; Wouters, K.; Gaens, K.; Hansen, D.; Bijnen, M.; Wetzels, S.; Stehouwer, C.D.; Goossens, G.H.; Schalkwijk, C.G.; Blaak, E.E.; et al. Abdominal Subcutaneous and Visceral Adipocyte Size, Lipolysis and Inflammation Relate to Insulin Resistance in Male Obese Humans. Sci. Rep. 2018, 8, 1-8. [CrossRef]

41. Monteiro, A.M.; Ferreira, G.; Duarte, H. Metabolic Activity in the Visceral and Subcutaneous Adipose Tissues by FDG-PET/CT in Obese Patients Avaliação Da Atividade Metabólica Do Tecido Adiposo Visceral e Subcutâneo Por FDG-PET/CT Em Doentes Obesos. Acta Med. Port. 2017, 30, 813-817. [CrossRef]

42. Lee, D.; Brellenthin, A.G.; Thompson, P.D.; Sui, X.; Lee, I.M.; Lavie, C.J. Running as a Key Lifestyle Medicine for Longevity. Prog. Cardiovasc. Dis. 2017, 60, 45-55. [CrossRef]

43. Pedisic, Z.; Shrestha, N.; Kovalchik, S.; Stamatakis, E.; Liangruenrom, N.; Grgic, J.; Titze, S.; Biddle, S.J.H.; Bauman, A.E.; Oja P. Is Running Associated with a Lower Risk of All-Cause, Cardiovascular and Cancer Mortality, and Is the More the Better? A Systematic Review and Meta-Analysis. Br. J. Sports Med. 2020, 54, 898-905. [CrossRef] [PubMed]

44. Chang, Y.H.; Yang, H.Y.; Shun, S.C. Effect of Exercise Intervention Dosage on Reducing Visceral Adipose Tissue: A Systematic Review and Network Meta-Analysis of Randomized Controlled Trials. Int. J. Obes. 2021, 45, 982-997. [CrossRef] [PubMed]

45. Bano, G.; Trevisan, C.; Carraro, S.; Solmi, M.; Luchini, C.; Stubbs, B.; Manzato, E.; Sergi, G.; Veronese, N. Inflammation and Sarcopenia: A Systematic Review and Meta-Analysis. Maturitas 2017, 96, 10-15. [CrossRef]

46. Czech Statistical Office. Gender: Education. Available online: https://www.czso.cz/csu/gender/1-gender_vzdelani (accessed on 25 April 2021). 